\title{
THE DIAGNOSTIC SUPPORT TOOL - QUALITY FUNCTION DEPLOYMENT AND ITS IMPLEMENTATION POSSIBILITES TO URBAN PUBLIC TRANSPORT QUALITY MANAGEMENT
}

This paper deals with the diagnostic support and its implementation possibilities to urban public transport quality management in the city of Zilina. It describes the Quality Function Deployment method with its own House of Quality tool along with its building. The complex building of the House of Quality was made in order to identify the key drivers needed to be improved for higher customers' satisfaction with the service quality.

Keywords: Quality Function Deployment, Diagnostic Support Tool, Urban Public Transport.

\section{Introduction}

For majority of people, the urban public transport is a part of their everyday lives. And is there anybody at all who has never used urban public means of transport to get from Point A to Point B?

Nowadays the number of people preferring individual car transport is increasing and this fact results into serious problem needed to be solved by the service operators. It is important to outline the main reasons why individual car transport is preferred and to become more responsive to customers' needs. In the city of Zilina there is one service operator - Dopravny podnik mesta Zilina, s. r. o. (DPMZ) whose customers decline in quantity each year. Urban public transport quality management offers several methods and techniques of the service improvement. Quality management diagnostic support is one of them. The aim of this paper is to find the necessary key information exploitable as a basic input for service operator decisions. This information is obtained by the implementation of the selected diagnostic support tool - Quality Function Deployment - generally used in quality management.

\section{Theoretical Basis}

\subsection{Fundamentals of Diagnostics}

Diagnostics has its primary basics in Pain and Remedy management. The pain is the reason why the system is being brought to the decision crossroad called Bifurcation point - the position with two possible ways to set out for.

A toothache is a very suitable and clear example for illustrating this. Everybody in their lives has suffered from the toothache. The toothache is accompanied by the pain and it represents the bifurcation point:

a) one will not see the dentist = one takes the risk for the pain may be worse, moreover the inflammation could accrue and this could lead to death (the worst scenario),

b) one will see the dentist = one would be cured of the pain, moreover the information about preceding the tooth decay can be given [1].

This is the main principle the diagnostics originates from. However, the diagnostics helps to identify the weak spot, it also hints at unused opportunities. The diagnostics helps to:

- tackle arisen problems (the toothache),

- precede adverse situations (the tooth decay).

Quality management diagnostic support offers the extensity tools which can be used in the process of planning the service quality, its implementation or even in the process of its evaluation. Diagnostic support tools help to find and choose the information needed most for repressing the adverse situation along with detecting the way of its effective solving.

\footnotetext{
* Ivana Andriskova, Mariana Strenitzerova

Department of Communications, Faculty of Operation and Economics of Transport and Communications, University of Zilina, Slovakia, E-mail: Ivana.Andriskova@fpedas.uniza.sk
} 


\subsection{Current Situation Analysis}

In the city of Zilina DPMZ has been providing the urban public transport service since November $1^{\text {st }}, 1993$. The service is provided for inhabitants in order to meet the everyday transport needs (commuting to work, school etc.) and represents very important social-economic component which the environment consist of. To comply with the customers' requirements the quality of service has to be enhanced. The object of the current situation analysis is DPMZ quality management system and its ability to match the customers' needs and preferences.

In the Slovak Republic the framework for urban public transport field goes from the European norm 13816:2002. The Slovak version has the same identification numbers and it is named: Transportation. Logistics and services. Public passenger transport. Service quality definition, targeting and measurement [2]. According to this framework the service quality is divided into eight categories and each category of the service quality is specified to details - in fact, these eight categories cover 103 service attributes however, the customers do not rate the service according to as many criteria as the norm suggests [3].

Except for the European norm (which is basic and the most important framework) the bearer quality management frame of urban public transport implies also the ISO certification and audit even though the audit has already been a part of the diagnostic support. The quality management diagnostic support tools are used by service operators less often and assimilation rate differs

\section{Overview}

Quantity of passengers transported per year and yearly income from public urban transport

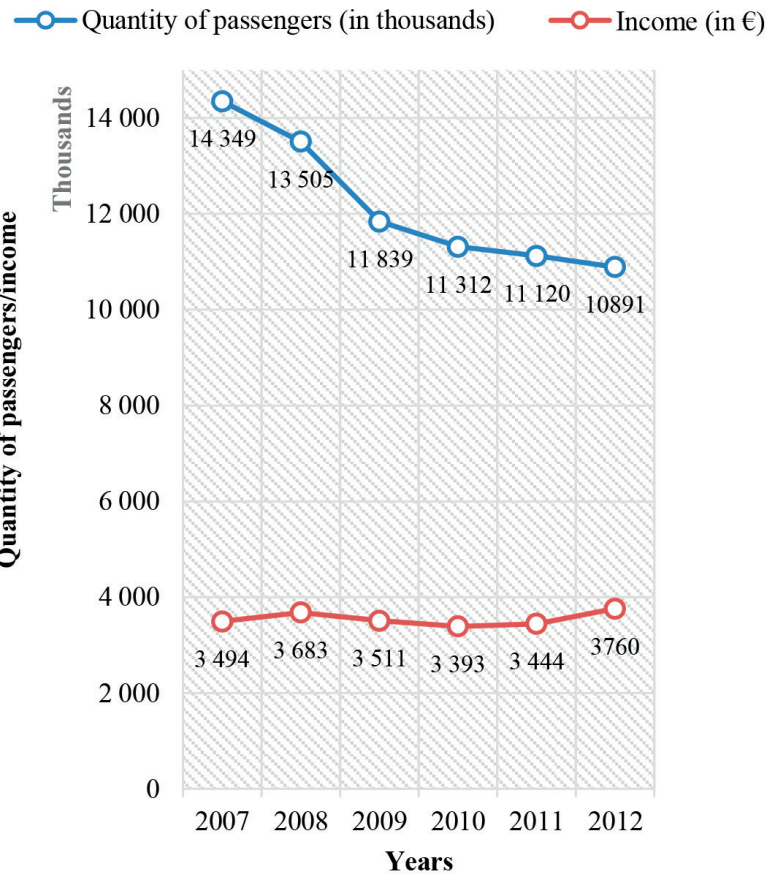

Fig. 1 Overview - The Quantity of Passengers and Yearly Income (Source: compiled by the authors on the base of DPMZ annual reports)

Urban Public Transport Quality Management

\begin{tabular}{|c|c|c|}
\hline \multicolumn{3}{|l|}{ Basic framework } \\
\hline EN 13816 & $\emptyset$ & $\forall$ \\
\hline ISO certification & $\begin{array}{c}\uparrow \\
\text { increasing tendency }\end{array}$ & $x$ \\
\hline $\begin{array}{l}\text { Internal guidelines } \\
\text { (amendment to EN) }\end{array}$ & $\begin{array}{l}\text { individually } \\
\text { (at the discretion of service operator) }\end{array}$ & 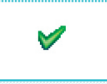 \\
\hline \multicolumn{3}{|l|}{ Diagnostic support tools } \\
\hline D Audit & $\begin{array}{c}\uparrow \\
\text { increasing tendency }\end{array}$ & $x$ \\
\hline Denchmarking & $\begin{array}{c}\text { low rate } \\
\text { (mostly in big cities in Europe) }\end{array}$ & $x$ \\
\hline \multirow[t]{2}{*}{ Dther tools } & $\begin{array}{c}\text { individually } \\
\text { (depends on faced problem) }\end{array}$ & $x$ \\
\hline & Service operators generally & $D P M Z$ \\
\hline
\end{tabular}

Source: Authors 
from one service operator to another. Overview in Table 1 shows the assimilation rate comparison between service operators in general and the service operator in Zilina DPMZ separately. The information was gained thanks to internal information given by some service operators and accomplished secondary research.

The most reliable indicator showing whether the current quality management system in DPMZ is adequate to customers' requirements or not, is the quantity of passengers transported per year. Information being annually published in DPMZ annual reports experiences the decline. During the last six years (20072012) the quantity of passengers transported/year decreased by 3200000 , however the yearly income from the urban public transport remains at the same level each year (Fig. 1) - this is caused by increasing transport ticket prices.

The quality management system in DPMZ is not sufficient for the market needs and, therefore, the service operator should pay more attention to customers. In the deciding process the reducing passenger numbers symbolize a bifurcation point. For both sakes (the operator and customers) it is necessary to upgrade the quality management system with the diagnostic support tools focused on customers and their requirements. Higher transport ticket prices along with higher quality of services - but still adequate to the ticket price - would affect the customers' willingness to pay.

\section{The Research Methodology}

The main objective, rising from the current situation analysis, is to obtain more effective quality management system in DPMZ which would lead to higher customers' trust. This could be achieved by selecting an appropriate diagnostic support tool. When selecting a tool the major purpose to have in mind should be following:

- stabilisation of the quantity of passengers,

- improving the quality service provided,

- enhancing the customers' satisfaction.

\section{Quality Function Deployment}

\subsection{Selecting the Tool}

The technique of mind map was used for selecting an appropriate diagnostic support tool. It helps to detect the structure graphically and linked relations which are important to see.

Complying with the major purpose (mentioned above) the selected method is Quality Function Deployment (QFD) with its specific tool named The House of Quality because:

- it is based on customers' requirements,

- it is commonly used in the planning phase of the service quality, but has its own justification in cases the service is already provided but it has some weak spots and the service operator faces the loss of customers,

- DPMŽ has no experiences with the diagnostic support tools and the QFD method used in the planning process of quality seems to be applicable,

- the successful building of the House of Quality would result into meeting the major purpose in order to improve the current quality management system in DPMZ accompanied with a higher customers trust.

\subsection{Building the House of Quality}

The House of Quality is a very complex diagnostic support tool. It combines multiple sub-analyses which differ from each other in difficulty of processing, in types of data input (primary research/secondary research) and in the total time needed for their successful building (Fig. 2)

As the range of this paper does not allow describing each step in detail, only the final results are presented.

The essential and most important step was to identify customers' requirements they have when thinking about quality of urban public transport. It was done by applying the Critical to Quality method which comes from the Voice of Customers. As mentioned in the section 2.2 Current Situation Analysis the European norm consists of 103 quality service attributes, even though customers use their own characterization - they are not so specific in certain cases and some of the attributes are described widely. It means that one customer requirement can include more than one service attribute determined by the European norm. This information is considerable for a service operator as it helps to focus on necessary service attributes.

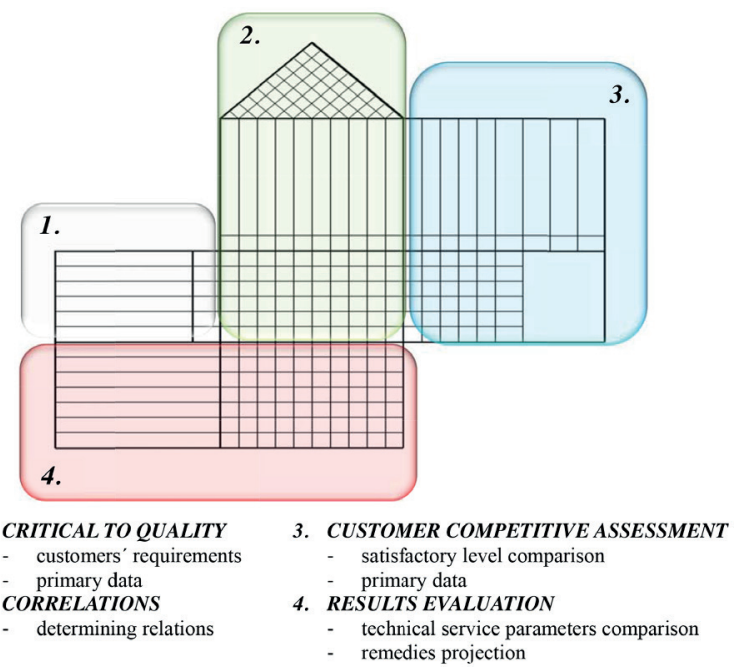

Fig. 2 Different approaches in the House of Quality (Source: Authors) 
Customers identified fifteen key requirements which represent drivers of satisfaction when talking about delivered service quality.

After identifying drivers of satisfaction and their significance (weight) the technical service parameters which affect the fulfilment of requirements were assigned to each, for example:

\section{Customary requirement is affected by the technical service parameter \\ Timetable keeping $\leftrightarrow \leftrightarrow \quad \emptyset$ delay in seconds}

The correlations among each chosen requirement and each service parameter could be done afterwards. When rating the service quality, four key technical service parameters affect customers most. They play a major part in deciding about using the urban public transport or individual car transport. If the customer rates them with high satisfactory score, he prefers the urban public transport. If the score is low, he turns his preferences to individual transport. These are the most important technical service parameters:

1. Ø number of line connection/hour,

2. Ø time waiting for the next line connection in minutes,

3. Ø delay in seconds,

4. Tariff in $€ / \mathrm{km}$.

The second primary research deals with Customer competitive assessment. The customers' 15 drivers of satisfaction were compared to the service quality delivered in other four Slovak cities. Thanks to this rating we are able to see the customer satisfaction score with each requirement even in each city, to define overall satisfaction and calculate total quality service perceived by customers in each city separately.

Drivers of satisfaction score

Table 2

\begin{tabular}{ll|lr} 
SATISFIED WITH & Score & DISSATISFIED WITH & Score \\
\hline \hline Timetable keeping & & & 2.49 \\
Frequency in rush hours & 2.90 & Frequency off peak & 2.49 \\
Barrier-free access & 2.84 & Bus driver driving skills & 2.45 \\
Travel time & 2.81 & Functioning ticket machines on bus stops & 2.41 \\
Reliability & 2.78 & Ticket office opening hours & 2.38 \\
Bus cleanliness & 2.77 & Bus indoor temperature adequacy & 2.19 \\
Bus stop condition & 2.68 & Staff behaviour & 1.96 \\
Lines continuity & 2.68 & Price &
\end{tabular}

\begin{tabular}{cccc}
\hline \hline strongly agree & agree & disagree & strongly disagree \\
$(4.00-3.26)$ & $(3.25-2.51)$ & $(2.50-1.76)$ & $(1.75-1.00)$
\end{tabular}

Source: Authors

\section{How to gain new customers}

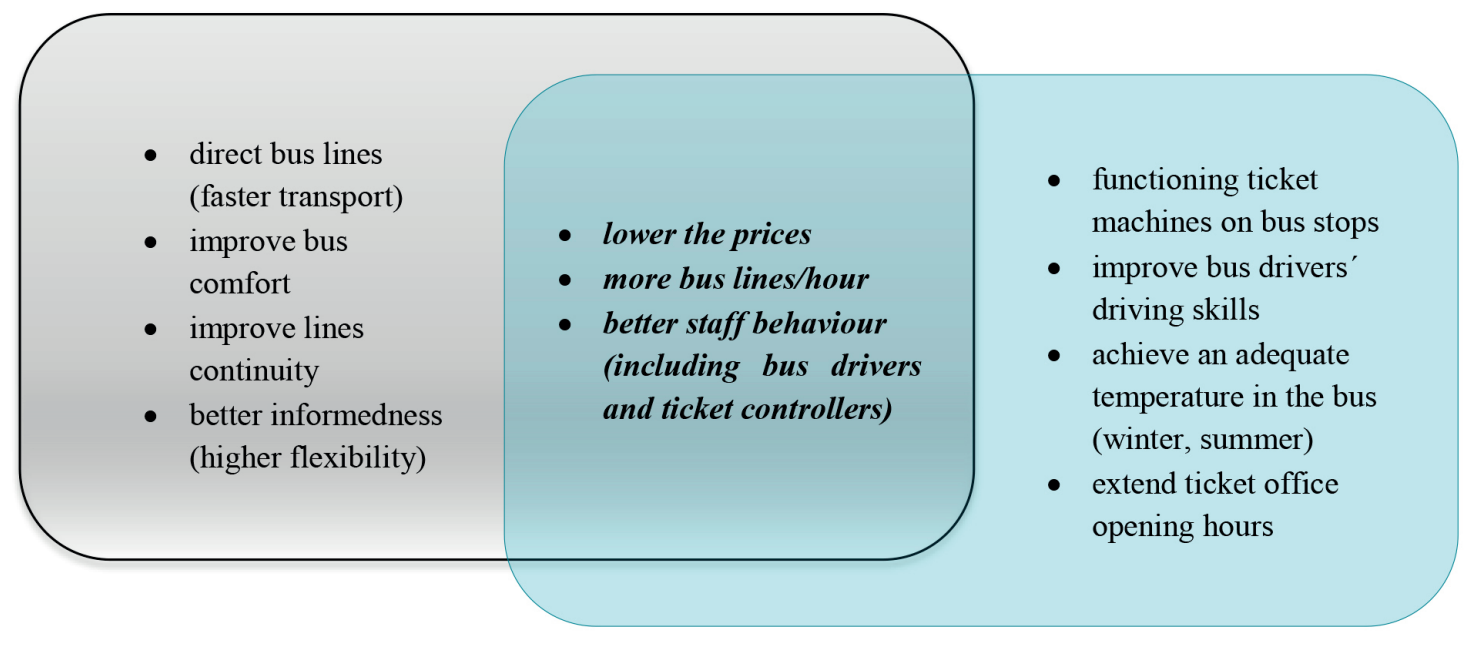

How to satisfied current customers

Fig. 3 How to achieve higher score of customers' satisfaction (Source: Authors) 
Zilina took the fourth place. Complete order of cities according to descending level of satisfaction is as follows:

1. Banska Bystrica - the most satisfied customers,

2. Bratislava,

3. Kosice,

4. Zilina,

5. Povazska Bystrica - the least satisfied customers.

When rating the customer satisfaction level with chosen requirements in Zilina, almost half of them - exactly 7 - cause the customers dissatisfaction. Likert-type scale rate ranged from strongly disagree, disagree, agree and strongly agree. Table 2 shows the overall situation.

The result is noticeable to the service operator because the pros of using urban public transport are almost equal to its cons in general, even though each requirement has its own weight and importance - however, the weight of some service attributes is crucial as the quantity of passengers tends to decline (Fig. 1). The service delivered does not match the sought service quality and this leads to preferring the individual car transport. Each of rated requirements is important for current customers but some of them are significant for people preferring individual car transport only. The research has detected the factors important when deciding whether to choose urban public transport or individual car transport. Upcoming Figure 3 detects the improving service possibilities for routine commuters and for people preferring cars. The conjunction of two parts is in the middle of the figure. These factors are important for both categories. However, the current customers' satisfaction would also increase after improving the factors significant to customers preferring the individual car transport.

\subsection{Staff Behaviour}

The staff behaviour was chosen as the most deep-going factor of the service quality (except for the price). This driver of satisfaction indicates very low score not only in Zilina but in each compared city. Staff behaviour has the lowest average score among all 15 drivers of satisfaction.

When projecting such a complex service as urban public transport is, we often unwittingly focus on technical service parameters while forgetting that the service is provided by people to people (by operator staff to passengers). This means both sides have their own participation in the service quality. The routine commuters cannot avoid getting in touch with operator staff - including bus drivers, ticket controllers, ticket office sellers. Behaviour is rated very anxiously and affects service quality in a less visible and psychological but in even more significant way. Staff behaviour quality elements consisting of staff skill, knowledge and attitude toward the customer may be:

- The staff behaves nicely and correctly.

- The staff answers questions correctly.
The staff represents the operator and the company culture. Employee behaviour and relationship quality impact on customers research shows that service orientation (the operator views interactions with customers as an opportunity to please them, providing a prompt service, having a reputation for good service, is being committed to service customers) affects relationship satisfaction and trust, and that the latter influences satisfaction and commitment (loyalty). In turn, satisfaction, trust and commitment have a positive impact on positive behavioural intentions, trust a negative one on activism (switching to a competitor if customer experiences problem with the service, complaining to external agencies, complaining to other customers), and commitment a positive one on perceived switching costs [4]. This may be a reason why staff behaviour is a significant service attribute to routine commuters and also the ones who had switched to individual car transport.

However, it is hard to generalize as every driver of satisfaction can be also influenced by parameters which are not part of The House of Quality such as traffic situation or transport infrastructure in the city etc. It is found that traffic quality can be an important goal on the one hand. On the other hand, traffic quality can be used to influence many decisions of road management and planning and, thereby, to reach other goals [5]. These correlations can be objectives of further research.

\subsection{The House of Quality}

Figure 3 shows completely processed House of Quality. More detailed description of each sub-analysis along with research results is disclosed in the section above.

\section{Conclusions}

The Technical Competitive Assessment is the last part of the House of Quality and we were only allowed to obtain data information from DPMZ thanks to the internal operator assessment. Following remedies projection is a continuous but self-dependent part of research.

The selected diagnostic support tool meets the major purpose it was chosen for. The several sub-analyses were found very useful for detecting and seeing all the factors along with key factors needed to be improved by the service operator. Thanks to uncovering the customers' requirements, identifying the correlations hidden between customers' requirements and technical service parameters and competitors comparison, it is easy to know the critical service possibilities of improving. After identifying the bifurcation point in the analysis part, the information coming from the House of Quality helps to tackle arisen problem and to precede adverse situations. Just the same thing as the fundamentals of diagnostics say. 


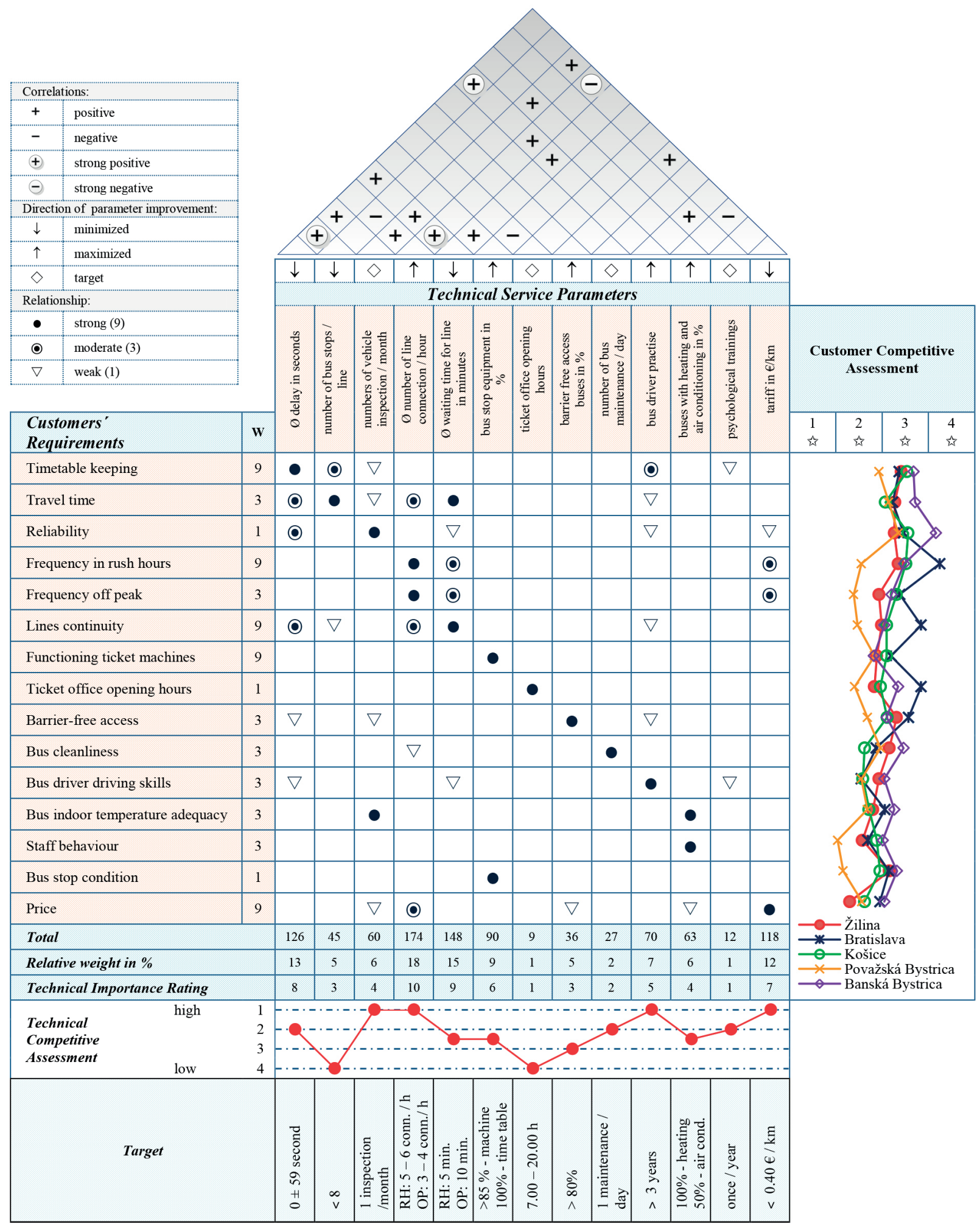

Fig. 4 Complete House of Quality (Source: Authors) 
The result highlights the importance of staff and cost-friendly public transport service. The research conclusion was released to DPMZ in order to trap the service attributes with low score of satisfaction. DPMZ decided to use a questionnaire survey research considering mainly the staff behaviour which seems to be a good step from bifurcation point as it could uptick the customers' loyalty in a longer time period. The higher interest in communication with customers would strengthen the customers' satisfaction and impacts on increasing numbers of people who decided for urban public transport in their everyday lives.

\section{Acknowledgements}

We are grateful to Jan Simko for helping us to obtain information about technical competitive assessment and Tatiana Corejova for her support and contributions to this paper. All errors remain ours.

Grant support:

Modelovanie difuzie znalosti v podnikovych hodnotovych retazcoch [Modelling of knowledge diffusion in business value chains]. Project VEGA 1/0421/12.

\section{References}

[1] HAUSER, S.: Crisis Management in a Turbulent Environment (in Czech). Opava, 2007. Online available: <http://www.slu.cz/ math/cz/knihovna/ucebni-texty/Krizove-rizeni-v-turbulentnimprostredi/Krizove-rizeni-v-turbulentnim-prostredi.pdf $>$

[2] KENDRA M.: Measuring the Service Quality of Public Transport Services (in Slovak). 2009. Online available: <http://fpedas. uniza.sk/zdal/images/stories/clanky_pdf/ cislo_03_09/08_kendra.pdf>

[3] STN EN 13816 Transportation. Logistics and Services. Public Passenger Transport. Service Quality Definition, Targeting and Measurement.

[4] BEATSON, A. T., LINGS, I., GUDERGAN, S.: Employee behaviour and Relationship Quality: Impact on Customers. 2008. Online available: $<$ http://eprints.qut.edu.au/20535/1/c20535.pdf $>$.

[5] KOREN, C.: Traffic Quality and its Management in Urban Areas. Zilina. 1999. Communications - Scientific Letters of the University of Zilina. Online available: <http://www.uniza.sk/komunikacie/archiv/1999/4/4_1999en.pdf> ISSN 1335-4205. 